\title{
Motrivivencia
}

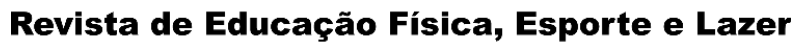

LaboMídia

\section{A cultura afro-brasileira na educação básica: um estudo sobre o exercício da lei 10.639/2003 em três escolas municipais de Tucuruí-PA}

\section{RESUMO}

Esta pesquisa tem como objetivo analisar como está sendo implementada a lei 10.639/2003 pelos professores de educação física no município de Tucuruí/PA. A metodologia utilizada caracteriza-se como uma pesquisa de campo que se constitui de uma abordagem quali-quanti com caráter exploratório e descritivo. Como instrumento de coleta de dados utilizamos o questionário estruturado com sete questões fechadas $\mathrm{e}$ relacionadas ao tema para professores de educação física das três escolas selecionadas para este estudo, todos de acordo com a legislação assinaram o termo de consentimento livre e esclarecido (TCLE). Os resultados mostraram que referente ao saber da lei $10.639 / 2003$, apenas $20 \%$ dos participantes afirmou conhecer esta lei, 95\% acreditam que o PPP da escola não contempla a discussão desta temática, fator que contribui para o preconceito racial na educação básica, que teve $70 \%$ de reconhecimento a existência no cotidiano das escolas brasileiras. Diante da pesquisa realizada, constatou-se que a lei $10.639 / 2003$ vem sendo pouco ministrada no cotidiano das escolas municipais contempladas. Os trabalhos realizados que abrangem a presente temática são abordados apenas na semana da consciência negra. Este estudo teve como referência artigos publicados em revistas cientificas, Google acadêmico e sites de pesquisa acadêmica.

PALAVRAS-CHAVE: Lei 10.639/2003; Educação afro-brasileira; Educação física
Jonatha Pereira Bugarim

Mestrando em Administração

Facultad Interamericana de Ciências Sociales - FICS

Grupo de pesquisa Educação, Currículo e

Diversidade na Amazônia Asunción, Paraguai

https://orcid.org/0000-0002-1744-3997

Maria da Conceição Pereira Bugarim Doutorado em Educação e Comunicação

Universidad Católica de Murcia

Grupo de pesquisa Educação, Currículo e Diversidade na Amazônia

Murcia, Espanha

E-mail: cbugarim@yahoo.com

https://orcid.org/0000-0003-1338-5504

Andréia do Socorro de Andrade da Costa

Pós-graduanda em Educação Especial inclusiva

Pós-graduanda em Administração, Gestão e Orientação Educacional UNIASSELVI

Cametá, Pará, Brasil Email: andreiacastroandrade94@hotmail.com - https://orcid.org/0000-0003-2021-4674

Rayná Benedita Sabóia de Oliveira Pós-graduada em Educação Física Escolar

UNIASSELVI

Cametá, Pará, Brasil

Email: raynahh_saboia@hotmail.com https://orcid.org/0000-0002-9415-9551 


\title{
Afro-brazilian culture in basic education: a study on the exercise of law 10.639 / 2003 in three municipal schools of Tucuruí-PA
}

\begin{abstract}
This research aims to analyze how the Law 10.639 / 2003 is being implemented by physical education teachers in the municipality of Tucuruí / PA. A methodology used is characterized as a field research that consists of a qualitative approach with exploratory and descriptive character. As an instrument of data collection used by the questionnaire structured with seven closed questions related to the subject for physical education teachers from the three schools selected for this study, all according to the legislation signed the informed consent form. The results are related to the knowledge of law 10.639 / 2003, only $20 \%$ of the participants said they know this article, $95 \%$ believe that the school PPP does not contemplate the discursion of this theme, a factor that contributes to racial prejudice in basic education, which had $70 \%$ recognition of the existence in the daily life of Brazilian schools. In view of the research carried out, it was verified that Law 10.639 / 2003 has been little taught in the daily life of the municipal schools contemplated. The works carried out and covering a thematic present are addressed only in the week of black consciousness. This study had as reference articles published in scientific journals, Google academic and academic research sites.
\end{abstract}

KEYWORDS: Law 10.639 / 2003; Afro-brazilian education; Physical education

\section{Cultura afro-brasileña en educación básica: un estudio sobre el ejercicio de la ley 10.639 / 2003 en tres escuelas municipales en Tucuruí-PA}

\section{RESUMEN}

El objetivo de esta investigación es analizar cómo los maestros de educación física implementan la ley 10.639 / 2003 en la ciudad de Tucuruí / PA. La metodología utilizada se caracteriza como una investigación de campo que consiste en un enfoque cuali-cuanti con un carácter exploratorio y descriptivo. Como instrumento de recolección de datos, utilizamos el cuestionario estructurado con siete preguntas cerradas relacionadas con el tema para maestros de educación física de las tres escuelas seleccionadas para este estudio, todo de acuerdo con la legislación firmada el formulario de consentimiento libre e informado (ICF). Los resultados mostraron que con respecto al conocimiento de la ley 10.639 / 2003, solo el 20\% de los participantes dijeron que conocían esta ley, el 95\% cree que el PPP de la escuela no incluye la discusión de este tema, un factor que contribuye al prejuicio racial en la educación básica, que El 70\% reconoció la existencia en la vida cotidiana de las escuelas brasileñas. En vista de la investigación realizada, se encontró que la ley 10.639 / 2003 ha sido poco administrada en la vida diaria de las escuelas municipales contempladas. Los trabajos realizados que cubren el tema actual se abordan solo durante la Semana de la Conciencia Negra. Este estudio se basó en artículos publicados en revistas científicas, sitios académicos y de investigación académica de Google.

PALABRAS-CLAVE: Ley 10.639 / 2003; Educación afro-brasileña; Educación física 


\section{INTRODUÇÃO}

A discussão deste artigo vem reforçar a importância do negro na formação da cultura Afrobrasileira. Buscando formas de reparar os danos causados aos negros, eliminar as diferenças entre raças, na promoção da igualdade de direitos, construir e educar uma sociedade que valorize e respeite a diversidade cultural, em 9 de Janeiro de 2003, foi sancionada a lei federal $\mathrm{n}^{\circ} 10.639 / 2003$ que torna obrigatório o ensino da história e cultura afro-brasileira e africana nas escolas do ensino fundamental e médio das redes públicas e privadas, municipais e estaduais.

Dada a importância da presença da cultura Afro-brasileira na educação nacional e de trabalharmos estudos que abordem a lei 10.639/2003, apresentamos como objetivo deste trabalho uma análise de como está sendo implementada a lei 10.639/2003, pelos professores de educação física do ensino Fundamental II, em três escolas municipais de Tucuruí.

Para alcançar o propósito da pesquisa foram definidos como objetivos específicos, qual a concepção dos professores de educação física no município de Tucuruí sobre o tratamento das questões raciais em suas aulas, buscar levantar informações a respeito do conhecimento que o professor de educação física no município de Tucuruí possui sobre a lei 10.639/2003, verificando a existência e utilização dos tipos de materiais didáticos utilizados pelas escolas que auxiliam no desenvolvimento do trabalho com o tema.

O estudo e a análise do presente temático são importantes para identificar se as propostas das diretrizes curriculares nacionais que tangem as relações étnico racial na educação básica estão tendo efeito no âmbito escolar, uma vez que, promover uma educação antirracista irá sustentar o modelo de desenvolvimento em que a diversidade seja um dos seus sustentáculos, na qual prevaleça a cultura da inclusão e da igualdade. Aprender e entender a importância das heranças africanas para o Brasil e seus descendentes é avançar na construção de um país democrático e justo.

A relevância desta investigação está presente em razão da obrigatoriedade da implementação da história e cultura dos povos Afro-brasileiros por parte das escolas, daí a importância de se verificar como os professores de educação física do ensino fundamental II no município de Tucuruí, vêm realizando a discussão e trabalhando esse tema com seus educandos. Já que a lei permite essa proximidade no âmbito escolar para fomentar ainda mais essa discussão em relação a esse objeto de estudo.

A situação problema que está causando interesse pela pesquisa é a deficiência observada nas redes de ensino quanto ao exercício da lei 10.639/2003 nos estabelecimentos fundamental e médio, das redes públicas e privadas. Somando-se a isso, outra dificuldade que podemos destacar é a ausência de recursos didáticos que dê subsídio para a aplicabilidade de uma educação multicultural 
na escola. Em outro giro, a falta de qualificação dos profissionais torna-se um dos alicerces para a desvalorização desse conteúdo, isso porque a lei foi criada, porém não houve uma mudança nas grades curriculares dos cursos de graduação que preparem os professores para trabalharem o conteúdo da história afro-brasileira e africana na educação básica.

No decorrer do nosso texto científico vamos trabalhar em cima das seguintes questões norteadoras: Os professores de educação física do ensino fundamental II do município de Tucuruí conhecem a lei 10.639/2003? O acesso à discussão da lei é disponibilizado pela rede de ensino para a escola? No planejamento da escola a temática está inserida? Como vem sendo abordado esse assunto em suas práticas pedagógicas?

Portanto, pretende-se descobrir como os professores de educação física no ensino fundamental II no município de Tucuruí estão trabalhando as questões que permeiam a lei 10.639, quais as dificuldades e os impactos que os mesmos estão causando no âmbito escolar.

\section{A INCLUSÃO DA HISTÓRIA E CULTURA AFRO-BRASILEIRA}

Segundo Borges (2010), a cultura e o padrão estético negro africano convivem no Brasil de maneira tensa com os padrões estéticos da cultura europeia. De acordo com o IBGE, a população brasileira sendo composta de $45 \%$ de pessoas negras, ainda convivem com ideologias, desigualdades e estereótipos racistas. Desta forma, temos um imaginário étnico-cultural que privilegia e valoriza a cultura europeia, ignorando ou pouco valorizando as que participaram da miscigenação brasileira como a indígena e africana.

Por volta dos anos 90, já se pensava na inserção do conteúdo da história da África na educação básica, porém, a ideia estava muito atrelada à questões como o tráfico negreiro, escravidão e ao quilombo de palmares. Essa concepção do negro atrelado ao sofrimento tem acarretado mudanças significativas como a promulgação da lei n 10.639/2003, pois essa proposta do conteúdo da África em sala, da ênfase na diversidade, identidade e diferenças culturais (MOREIRA, 2008).

Os ensinos da cultura Africana nas escolas darão oportunidades para os educadores colocarem em debate que os povos africanos nem sempre foram escravos, desagregando a imagem do negro somente à escravidão, em meio a isso é através desta educação cultural que é possível construir a valorização de uma sociedade que passe a enxergar a história de vida desse povo como uma história de luta e garra (NEVES, 2012).

Os efeitos das diversas manifestações culturais refletem em vários aspectos diários da cultura brasileira, quer sejam de berço europeu, africano ou indígena. Esses valores da cultura 
africana se fazem presentes, nas religiões, manifestações artísticas ou em outros elementos da sociedade (FERNANDES, 2005). Enfatizar a cultura afro-brasileira e africana nas escolas trará oportunidades aos alunos a constatarem que os modos e os costumes dos brasileiros estão bastante atrelados à cultura negra.

O distanciamento entre brancos e negros, foi o resultado da escravidão e ainda é nos dias atuais pelo racismo que ainda se faz presente na sociedade. Introduzida também no contexto escolar, uma vez que somos educados a enxergar as diferenças através das histórias de tensões e conflitos associados aos negros (GOMES, 2003).

Dessa forma, é importante observarmos que as escolas também são espaços, que disseminam as diferenças de raças, pois o modo que difundem a socialização do conhecimento e da cultura, afirmam as representações negativas sobre o negro. Porém, a escola também é local onde o preconceito pode ser superado, então ressaltamos a necessidade de incluir no componente curricular de ensino, temas em valorização à população negra e indígena.

\section{A implementação da lei 10.639/2003}

Segundo a LDB (Lei de Diretrizes e Bases da Educação), a lei 10.639/2003 foi sancionada pelo ex-presidente da república Luís Inácio Lula da Silva em 9 de janeiro em 2003, tornando obrigatória, no currículo da rede de ensino público e privado da educação básica, o ensino da história e cultura afro-brasileira e africana, essa lei vem atender as reivindicações dos movimentos negros que a muito tempo lutavam por essa conquista. Em 2004 foi aprovado pelo Conselho Nacional de educação, nas "Diretrizes Curriculares Nacionais" de educação para a educação das relações Étnico Raciais e para o Ensino de História e Cultura Afro-brasileira e africana:

Art.26-A- Nos estabelecimentos de ensino fundamental e médio, oficiais e particulares, torna-se obrigatório o ensino sobre história e Cultura AfroBrasileira.

Parágrafo Primeiro - O conteúdo programático a que se refere o caput deste artigo incluirá o estudo da África e dos Africanos, a luta dos negros no Brasil, a cultura negra brasileira e o negro na formação da sociedade nacional, resgatando a contribuição do povo negro nas áreas social, econômica e política, pertinentes à História do Brasil.

Parágrafo segundo - Os conteúdos referentes à História e Cultura AfroBrasileira serão ministrados no âmbito de todo currículo escolar em especial, nas áreas de Educação Artística e de Literatura e Histórias Brasileiras.

Art.79-B - O calendário escolar incluirá o dia 20 de novembro como "Dia Nacional da Consciência Negra". 
Dentre as questões que serão abordadas nas aulas incluíram o percurso do negro pelo Brasil, um estudo de valorização da cultura negra e a contribuição para o processo de miscigenação brasileira. Diante disso, os professores terão que buscar conhecimentos como um todo, como por exemplo, a contribuição do negro para economia, culinária, para as diferentes culturas envolvendo as danças, estilos musicais, a estética, entre outros as aspectos que estão atrelados à formação da cultura e identidade nacional.

É importante ressaltar que a obrigatoriedade da lei que envolve a história e cultura afrobrasileira deverá ser aplicada em todo âmbito escolar, dando ênfase principalmente nas áreas artísticas, literatura e história brasileira. Além disso, todas as escolas da educação básica terão que adotar no calendário escolar brasileiro o dia "20 de novembro como o Dia Nacional da Consciência Negra” (GUEDES; NUNES; ANDRADADE, 2013).

A busca pelo respeito e liberdade desse povo que foram arrancados de seus locais de origem é essencial, essa promoção ou conquista vieram acompanhadas da inserção desses conteúdos nas escolas, pois farão com que os alunos reconheçam que as diferenças entre negros e brancos sejam tidas como natural (HENRIQUE, 2005).

Apesar dos 13 anos da promulgação da lei 10.639/2003, percebe-se que as escolas pouco ou quase não trabalham essa temática, ou seja, as redes de ensino da educação básica público e privado não estão cumprindo a lei de forma efetiva, uma vez que essa contribuição seria de grande importância para alcançarmos o respeito e igualdade racial (EMBRAMOWICZ et al., 2012).

A lei $n^{\circ} 10.639 / 2003$ foi uma conquista para as leis direcionadas à educação, pois elas são ótimas oportunidades para irradiar o combate ao preconceito racial. A partir da implementação da lei, as escolas terão oportunidades de construir uma nova história, deixando de dá ênfase apenas à subordinação e sofrimento dos negros, e abrir caminhos para construção da verdadeira identidade própria e social dos negros. Aquela que abrange a diversidade de cultura, que foi de extrema importância para a formação da cultura brasileira. (FIGUEIREDO, 2012).

\section{Valorização da identidade cultural}

Segundo Silva (2013), a construção da identidade nacional brasileira, conta e se apoia, nas novas diretrizes e conteúdo da educação, onde se destacam os estudos das histórias e culturas afrobrasileiras, nos estabelecimentos de ensino fundamental e médio das redes públicas e privadas. A obrigatoriedade da lei contribui de forma significativa através dos conhecimentos e abordagem em valorização e destaque da cultura afro-brasileira, para a superação do racismo e das desigualdades 
raciais e, consequentemente, para implementação, consolidação e aceitação do orgulho e autoestima de ser negro.

Neste sentido, um dos pontos cruciais para o reconhecimento e valorização da cultura afrobrasileira surgiu a partir da lei federal 10.639/2003, em que os negros estão envolvidos desde a colonização até os dias atuais, de modo positivo e consciente da diversidade brasileira.

A identidade cultural é a construção de uma cultura repleta de elementos e significados que vão identificar esse povo como pertencente a uma determinada comunidade ou religião, diferenciando-os de outras comunidades ou religiões (SILVA, 2013). O autor também reforça que, a cultura de um povo deve se remeter à sua origem, seu princípio, sua memória cultural e suas raízes, com o objetivo de manter acesa a construção de sua própria história.

Qual o principal problema que aflige o outro que não aceita a pessoa negra? Qual o receio do outro em relação a pessoa ser negra? Diante de tais indagações, no que concerne à rejeição e aceitação do ser negro, uma ideologia errônea, que tenta a todo custo encobrir ascendência negra, e principalmente suas características como: o tipo de cabelo, cor da pele e o estilo de vida que levam. Essa concepção foi construída socialmente e isso não ocorreu de forma aleatória, mas existe um conjunto de fatores relacionados às questões históricas, sociais, culturais e políticas no Brasil.

Construir uma identidade negra positiva em uma sociedade que historicamente, ensina ao negro, desde muito cedo, que para ser aceito em sociedade é preciso negar-se a si mesmo, é um desafio que o brasileiro negro tem enfrentado desde o período do colonialismo. Os negros deparamse nas escolas, até mesmo dentro de casa, em ambientes públicos, seja no trabalho, nos espaços de lazer ou no ambiente escolar com olhares diferentes sobre o seu pertencimento racial, sobre a sua cultura, seu corpo e sua estética.

A concepção que inferioriza o negro de suas características corporais são padrões estéticos seguidos pelos brancos estabelecidos na sociedade. Uma das dificuldades enfrentadas pelo negro em assumir o seu próprio padrão estético, considerado pelo branco como sinônimo de feiura. Era a tentativa de excluir os valores culturais do outro, com a finalidade de destruir aos poucos a identidade negra, e com isso negar a existência de uma cultura considerada por eles como inferior (SOUZA, 2009).

A desconstrução da ideologia que desumaniza e desqualifica o negro e sua cultura, seus valores, suas características físicas pode contribuir de forma significativa para o processo de construção da identidade étnico racial e autoestima dos afrodescendentes, passo fundamental para a construção dos direitos de cidadania (SILVA, 2005).

Identificar e corrigir as diferentes formas de descrição de valores que os negros sofreram e que ainda refletem na sociedade atual é ensinar que a diferença pode ser superada, que além de ser 
bela, diversificada, ela pode ser enriquecedora. É um dos passos para a construção da autoestima, do autoconceito da cidadania e da abertura para o acolhimento dos valores das diversas culturas presentes na sociedade.

A construção da identidade de uma pessoa se dá na infância e vai sofrer influência de todos os referenciais com quais ele irá se deparar ao longo de sua história, sejam positivos ou negativos. Nessas circunstâncias, o processo acontecerá através de várias mudanças de personalidades que vai depender de construções de conceito e concepções positivas ou negativas na sociabilidade dela com outras pessoas (MARIOSA, 2011).

Quando a criança negra é inserida em outro grupo social que se diferencia de sua família, ela começa a perceber a diversidade social. No cotidiano escolar, ela constrói seu autoconceito de acordo como é vista pelo professor e pelos seus colegas de classe. É nas interações sociais que começa o processo de construção da identidade da criança, sendo de suma importância, neste momento, que ela encontre na escola elementos significativos referentes à sua etnia, favorecendo a percepção de sua autoestima diante dos traços que as diferenciam de outras crianças (SOUZA; CROSO, 2007).

No processo de construção da identidade cultural, a escola assume um importante papel: auxiliar as crianças a valorizarem suas características étnicas e culturais. Diante dos preconceitos de raça disseminados, principalmente no ambiente escolar, mesmo ela sendo um veículo de informação e saber, este âmbito deveria ser o meio mais eficaz na diminuição do racismo e, consequentemente, na valorização e aceitação da identidade da criança afro-brasileira.

Segundo Ferreira e Camargo (2011), a educação deve enfatizar as raízes e as histórias dos afro-brasileiros nos currículos de forma positiva, o brasileiro negro pode passar a valorizar suas características físicas, apresentar atitudes mais afirmativas frente às situações de descriminação e valores de raízes africanas.

\section{PROCEDIMENTOS METODOLOGICOS}

\section{Características da pesquisa}

A metodologia utilizada para esta pesquisa caracteriza-se como uma pesquisa de campo que se constitui de uma abordagem quali-quantitativa com caráter exploratório e descritivo.

A pesquisa quantitativa considera que tudo pode ser quantificável, o que significa traduzir em números opiniões e informações para inseri-las e analisá-las. (SILVA; MENEZES, 2005). Já a 
pesquisa qualitativa considera que há uma relação dinâmica entre o mundo real e o sujeito, ou seja, um vínculo indissociável entre o objetivo e subjetivo do sujeito que não pode ser traduzido em números (GUERRA, 2014).

A pesquisa exploratória visa proporcionar maior familiaridade com o problema, com vistas a inseri-lo explicitamente ou a construir hipóteses, envolvendo levantamento bibliográfico. (SILVA; MENEZES, 2005). Enquanto a pesquisa descritiva visa descrever as características de determinada população, fenômeno ou o estabelecimento de relações entre variáveis, envolvendo o uso de técnicas padronizadas de coleta de dados como, por exemplo, o questionário. (GIL, 2002).

A pesquisa foi realizada em três escolas das redes municipais de ensino fundamental II de Tucuruí: Rui Barbosa, Maria Fernandes e Dulcimar Brito.

Tabela 1: Populações amostra

\begin{tabular}{ccc}
\hline Escolas & $\mathbf{N}^{\mathbf{0}}$ de professores & Categoria \\
\hline EMEF Dulcimar Brito & 02 Professores & Fundam. II \\
EMEF Maria Fernandes & 02 Professores & Fundam. II \\
EMEF Rui Barbosa & 01 Professor & Fundam. II \\
\hline
\end{tabular}

\section{Critérios de inclusão}

Como critérios de inclusão, participaram do estudo, professores graduados em educação física, que atuam no segmento do ensino fundamental II e que exerçam a docência em sala de aula.

\section{Critérios de exclusão}

Quanto aos critérios de exclusão, não participaram da pesquisa, professores que estejam de licença prêmio, readaptado na função, formados em outra graduação e professores sem nível superior.

\section{Instrumentos e materiais}

Como instrumentos de coleta de dados utilizou-se o questionário estruturado com sete questões fechadas para professores, objetivando identificar os conhecimentos que eles detêm sobre a educação afro-brasileira e africana e as questões que permeiam a lei 10.639/2003 no âmbito escolar. 
Segundo Marconi e Lakatos (2003), a coleta de dados é um processo fundamental, porque fornece informações relacionadas aos acontecimentos, devendo estes serem analisados, descreverem situações, fatos e acontecimentos, assim como também comparar com dados da realidade presente para alcançar resultados.

\section{Procedimentos para a coleta de dados}

A princípio foi realizada uma reunião entre os pesquisados e os diretores (as) das escolas para que o mesmo tivesse conhecimento da pesquisa e do tema, assunto este que foi minuciosamente detalhado. Em cada escola entregamos um resumo do projeto com a problemática, objetivo do estudo e instrumento que foi utilizado para coleta das informações necessárias para esta pesquisa.

Posteriormente, entregamos a eles os documentos necessários para autorização de realização do estudo, que foi o termo de consentimento livre e esclarecido (TCLE), resumo do projeto e o questionário para os professores. Após a autorização, marcamos a data para aplicação do questionário. Este instrumento de coleta de dados continha sete questões fechadas com escalas diretamente relacionadas às perguntas.

A análise estatística foi realizada através de gráficos simples com a utilização da ferramenta do Microsoft Excel 2007, a análise e interpretação dos dados foram desenvolvidas de forma descritiva e analítica, dando ênfase no conteúdo. A análise das informações coletadas foi feita de forma qualitativa buscando interpretar os dados a partir da bibliografia levantada.

\section{DISCUSSÃO E RESULTADOS}

De acordo com a análise dos dados fornecida pelos professores das três escolas municipais de Tucuruí, são elas, Dulcimar Brito, Maria Fernandes e Rui Barbosa; tomadas como base para a realização desta pesquisa, após a aplicação do questionário constatamos que: quando questionamos sobre o conhecimento da lei 10.639/2003, 80\% dos professores relataram que já ouviram falar do assunto a respeito, $20 \%$ conhecem a lei e $0 \%$ não tem qualquer tipo de conhecimento. 
Gráfico 1 - Resposta a questão: Você conhece a lei 10.638/2003?

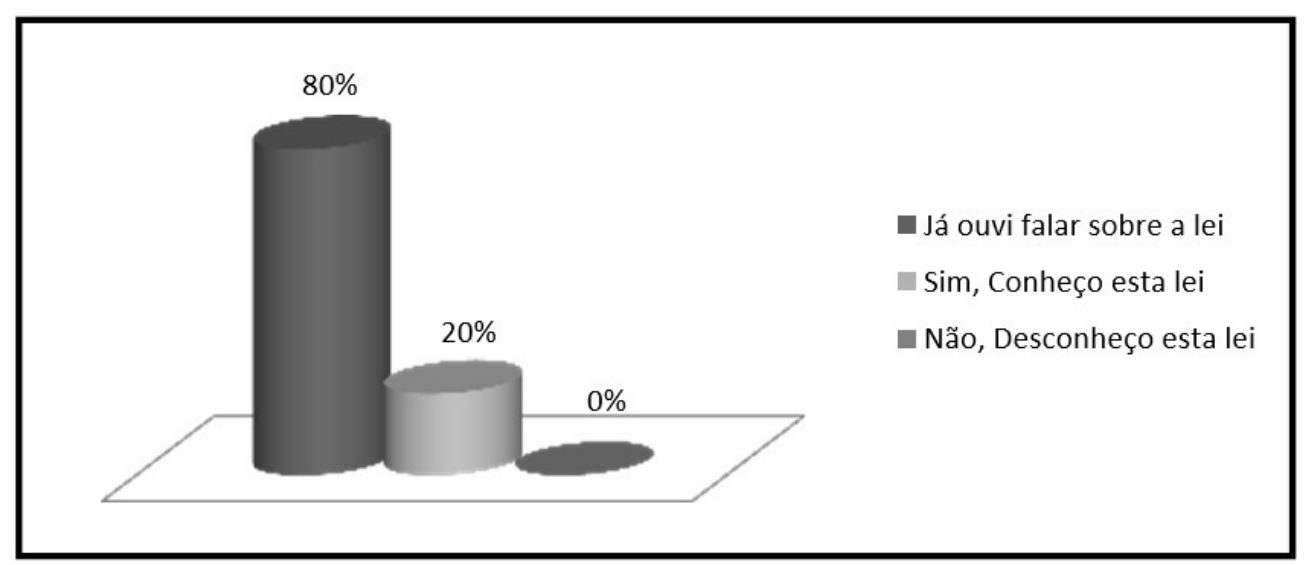

$\mathrm{Na}$ pesquisa, constatou-se que pequena parte entre os professores pesquisados há falta de conhecimento relacionado à lei implementada, diante do tempo que a mesma foi sancionada, podese observar que há uma ausência de discussões e planejamentos entre gestão das escolas voltadas para aplicabilidade desse conteúdo em sala de aula.

Segundo Moreira e Viana (2012), cabe aos municípios orientar as equipes gestoras e técnicas das secretarias de educação para implementação da lei 10.639/2003 nas instituições escolares. Pois este conhecimento transmitido na escola é importante para que possamos desmistificar a história do negro contada há anos atrás, valorizar e assegurar a diversidade cultural que é uma grande característica do nosso país.

Gráfico 2 - Formação continuada referente às relações étnico-raciais

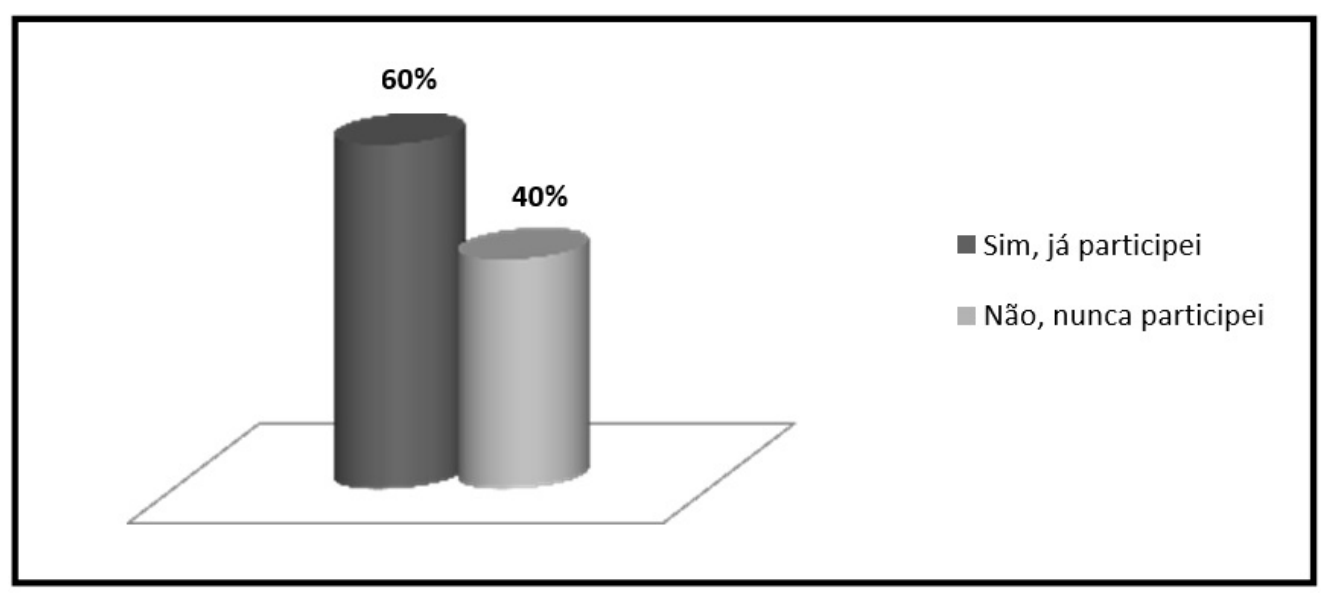

Lançada a pergunta sobre formação continuada para as relações étnico raciais, $60 \%$ dos professores responderam que já participaram de cursos relacionados à educação étnica racial, enquanto $40 \%$ disseram que nunca participaram desta formação. Embora este resultado seja 
negativo, pois corresponde quase à metade dos docentes pesquisados, a formação de professores para trabalhar com as questões étnico racial é de suma importância diante da implementação da lei. Para Garcia, Silva e Alexandre (2012), a formação acadêmica não teve em sua base uma abordagem metodológica que contemplasse a História e cultura do negro africano no Brasil, e a verdadeira historicidade deste povo de um modo geral.

É necessário que as escolas tenham professores preparados para lidar com as questões raciais nas aulas, pois é uma oportunidade dos alunos aprenderem um pouco mais sobre a história e cultura dos seus antepassados, e assim, assegurar a aplicabilidade da lei no cotidiano escolar.

Gráfico 3 - A relevância de trabalhar a cultura afro-brasileira nas escolas

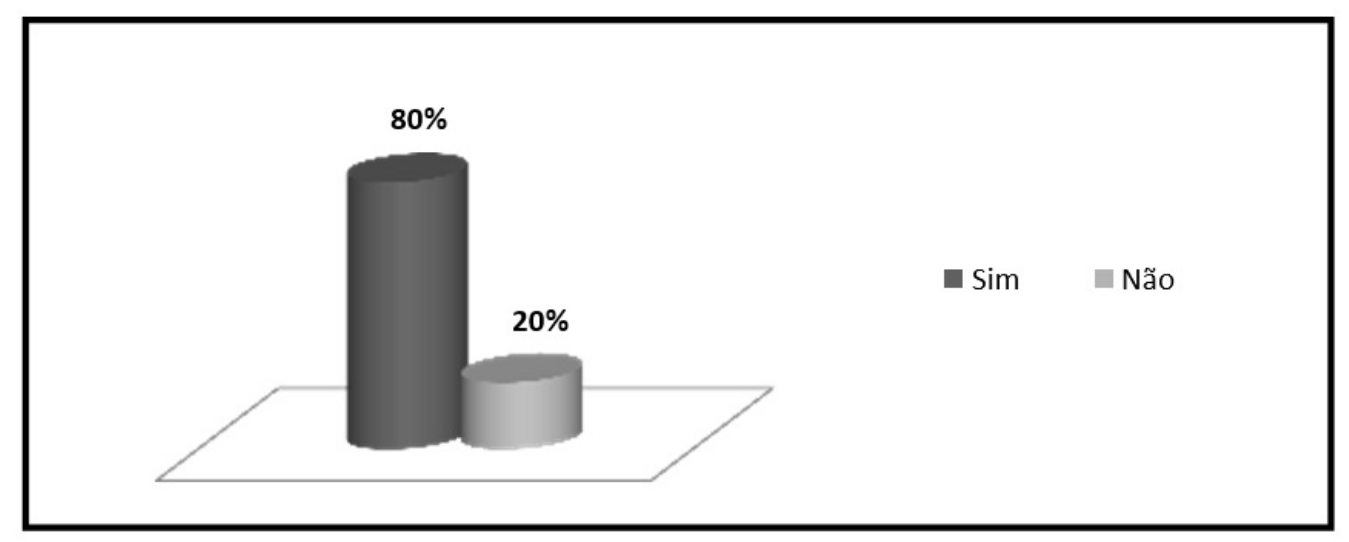

Trabalhar a aplicação desta temática nas escolas de educação básica é um avanço, uma vez que durante muito tempo a abordagem específica deste tema foi deixada de lado pelas escolas. Privando os alunos de participarem de forma direta no conhecimento da construção cultural, visto que, a educação é a base para criação de uma sociedade mais justa e menos discriminatória, para que, enfim, as diferenças da cultura Africana e Afro-brasileira sejam respeitadas.

Após a promulgação da lei 10.639/2003 é evidente os inúmeros benefícios quanto à aplicabilidade no âmbito escolar, no que diz respeito principalmente ao tratamento dado as questões étnico raciais, no qual eram tratados como "seres inferiores", marginalizados e passíveis de dominação, justificando assim o sistema escravista que por séculos sustentou a economia do Brasil. Também é notória a importância que o estudo e as discussões em sala de aula a respeito da História Africana possuem nos dias atuais. (GUEDES; NUNES E ANDRADE, 2013).

Quando questionamos: Você acha relevante trabalhar a cultura afro-brasileira na escola? $80 \%$ dos professores disseram que sim e $20 \%$ dos docentes apontaram não achar importante trabalhar esta temática. 
Trabalhar a aplicação desta temática nas escolas de educação básica é um avanço, uma vez que durante muito tempo a abordagem específica deste tema foi deixada de lado pelas escolas. Privando os alunos de participarem de forma direta no conhecimento da construção cultural, visto que, a educação é a base para criação de uma sociedade mais justa e menos discriminatória, para que, enfim, as diferenças da cultura Africana e Afro-brasileira sejam respeitadas.

Após a promulgação da lei 10.639/2003 é evidente os inúmeros benefícios quanto à aplicabilidade no âmbito escolar, no que diz respeito principalmente ao tratamento dado as questões étnico raciais, no qual eram tratados como "seres inferiores", marginalizados e passíveis de dominação, justificando assim o sistema escravista que por séculos sustentou a economia do Brasil. Também é notória a importância que o estudo e as discussões em sala de aula a respeito da História Africana possuem nos dias atuais. (GUEDES; NUNES E ANDRADE, 2013).

Quando questionamos: Você acha relevante trabalhar a cultura afro-brasileira na escola? $80 \%$ dos professores disseram que sim e $20 \%$ dos docentes apontaram não achar importante trabalhar está temática.

Gráfico 4 - O projeto político pedagógico na diversidade cultural

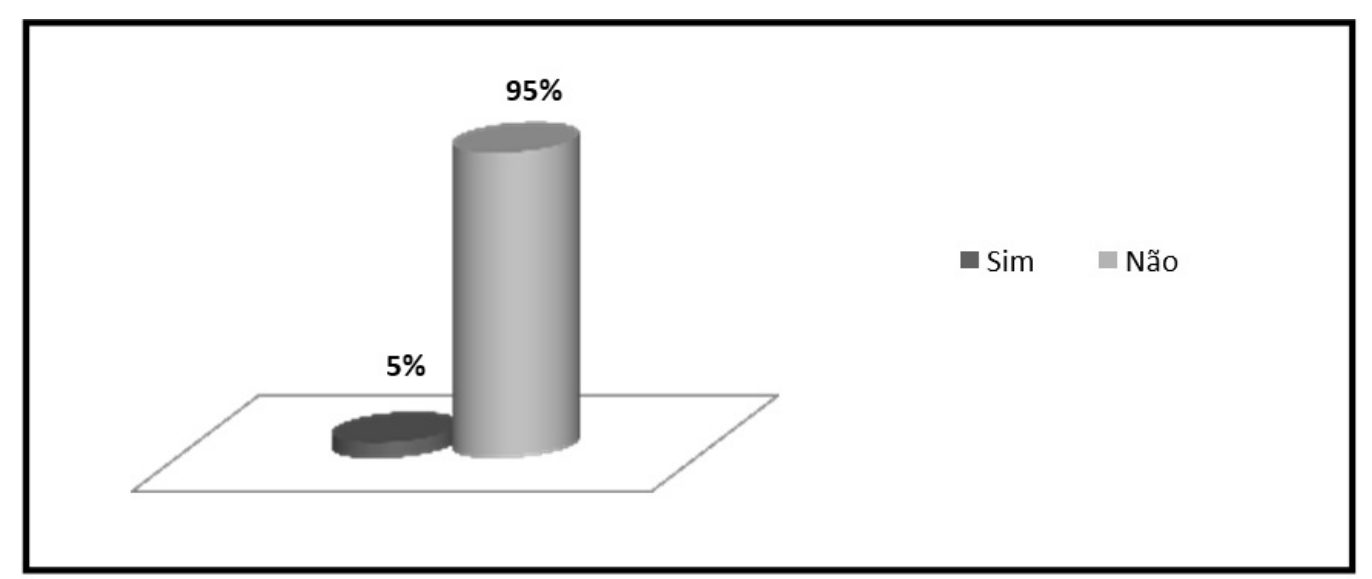

De um modo geral, podemos definir o Projeto Político Pedagógico (PPP) como o principal instrumento de um estabelecimento escolar. De acordo com Duarte e Silva (2013), o PPP permite que a escola demonstre sua identidade educativa. Trabalhando o característico sócio histórico, homem e sociedade que se pretende construir, visão da escola, entre outros. Assim, a ideia geral do projeto político pedagógico escolar é trabalhar uma visão ampla e diversificada, o que esta de acordo com a lei 10.639/2003 que visa contextualizar no âmbito educacional a valorização do multiculturalismo. Entretanto, diante dos professores pesquisados estas escolas não tem dado devido suporte para realização do exercício da lei 10.639/2003, haja vista que essa temática é 
trabalhada nas escolas em apenas um período anual, que é 20 de novembro, dia da consciência negra.

Gráfico 5 - Discriminação racial no contexto escolar

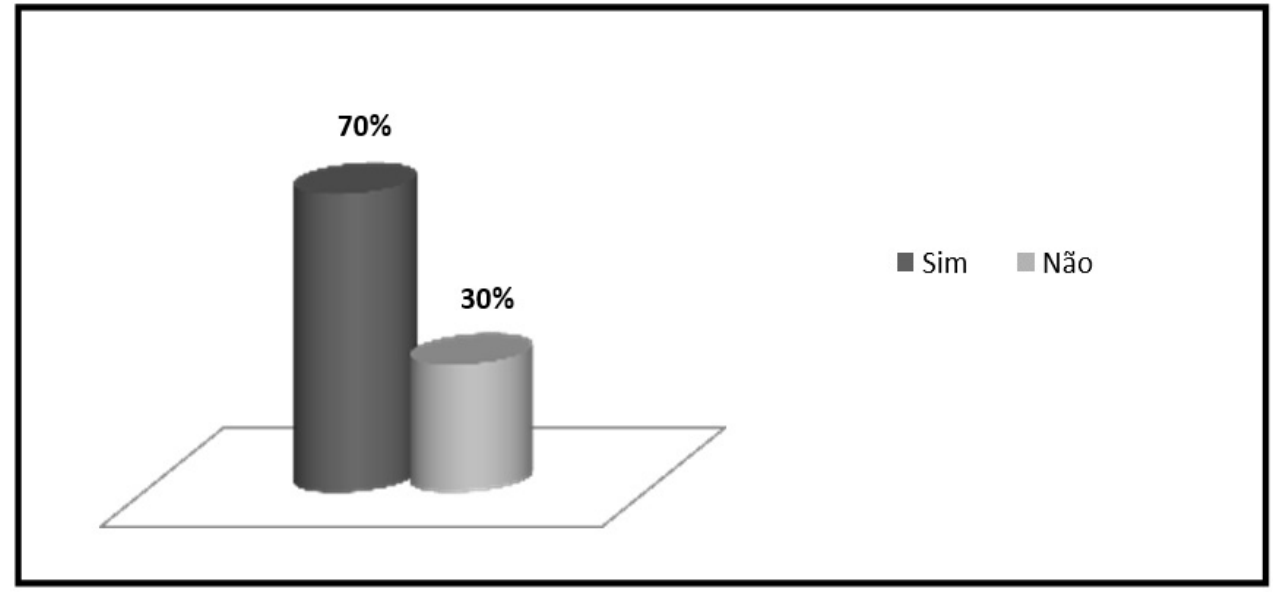

Com base nos resultados da pesquisa em relação à discriminação racial nas escolas brasileiras, $70 \%$ dos docentes reconhecem a existência do preconceito racial e 30\% acreditam não existir. Diante dos dados negativos do preconceito no cotidiano escolar, ressaltamos a importância do exercício da lei 10.639/2003 desde a primeira infância, isso porque, romper com preconceito e discriminação que já vem se arrastando há séculos na sociedade, não é uma tarefa fácil.

A formação do caráter de uma pessoa começa na primeira infância, fase que a mesma inicia seu processo educacional e as escolas são espaços que difundem a socialização do conhecimento da cultura. Segundo Souza (2017), a escola tem o papel de formar bons cidadãos, que sejam capazes de respeitar o próximo como a si mesmo. Sendo assim, trabalhar as questões étnico-raciais e culturais com as crianças pequenas, pode trazer resultados positivos, uma vez que elas irão aprender a conviver com as diferenças.

Gráfico 6 - preconceito racial e o debate nas reuniões de pais e alunos

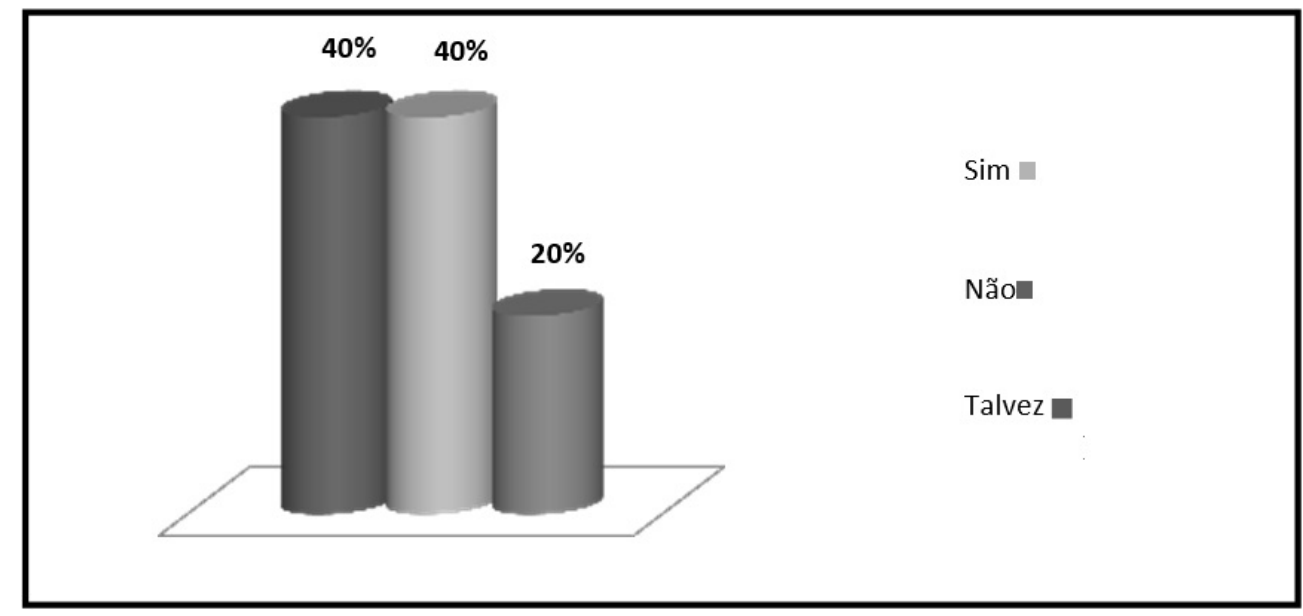


É de suma importância apresentar as ocorrências de discriminação racial aos familiares, tanto de pais, onde seus filhos foram alvo de discriminação, quanto aos familiares do autor de atos preconceituosos. Pois a escola tem como objetivo formar bons cidadãos, a família e a sociedade estão inseridas no processo de desenvolvimento social da criança. Há uma necessidade das escolas chamarem a comunidade para discursão das relações étnico-raciais, seja através de palestras ou atividades desenvolvidas com seus filhos dentro da escola, pois a igualdade racial precisa alcançar a todos.

Segundo Alves (2012), ninguém nasce com preconceitos, mas estes são aprendidos na nossa sociedade humana, dizemos que eles são aprendidos com outras pessoas nas relações sociais. Sendo assim, devemos observar que os primeiros julgamentos preconceituosos raciais demonstrados pelas crianças são frutos de seu aprendizado, de seu contato com adultos tanto no seu convívio escolar quanto no familiar.

Quando questionados sobre as reuniões de pais e responsáveis o debate do preconceito racial no âmbito escolar, 40\% dos professores disseram que sim, que há uma conversa da instituição sobre o tema com os familiares, $40 \%$ disseram que não e $20 \%$ afirmaram talvez.

Gráfico 7 - Materiais didáticos para trabalhar a cultura afro-brasileira

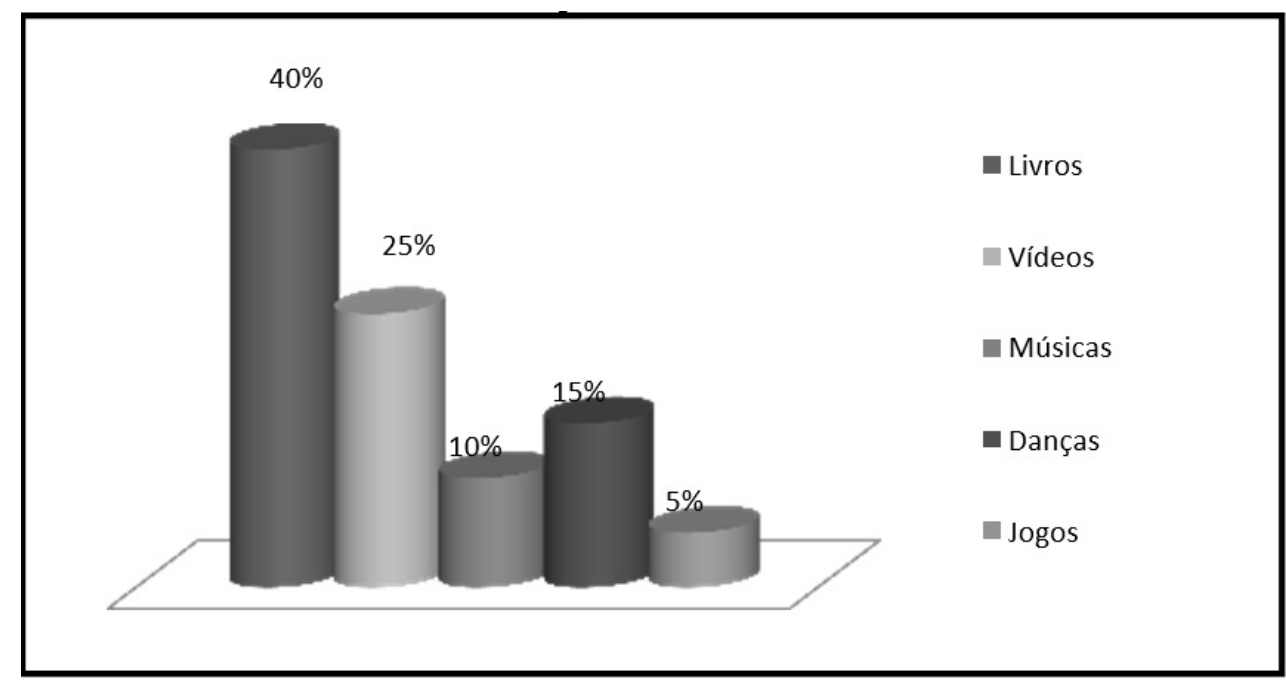

Este item apontou os livros como material didático mais utilizado pelas escolas, este é um ponto importante, pois a partir da Lei 10.639/03, os conteúdos Africanos e afros brasileiros foram inseridos no âmbito escolar e, consequentemente, no livro didático, um dos elementos norteadores do ensino em sala de aula. Porém, compreende-se até hoje que esse material de apoio possui um 
grande poder de reafirmar ideologias e transmitir preconceitos em seus conteúdos, contribuindo para que a escola seja parcialmente responsável por disseminar preconceitos de diversas formas.

Com isso, analisando as aulas de educação física, especificamente, seria interessante que os professores pudessem inserir com mais frequência atividades que trabalhassem não só o contexto teórico da tematização como também uma parte prática, dando ênfase à cultura corporal tão trabalhada pela cultura africana e Afro-brasileira. As danças, músicas e jogos seriam grandes destaques na aplicação destas aulas, colocaria em prática a nova visão de valorização da identidade cultural.

De acordo com Silva (2014) é interessante pesquisar e conhecer as manifestações corporais que tem sua origem vinculada à cultura africana e consequentemente à brasileira e transpô-las das diversas formas para uma intervenção dentro da disciplina de Educação Física, já que diferentemente das outras disciplinas curriculares, essa permite o contato corporal e principalmente afetivo entres os alunos.

Quando questionados a respeito dos materiais utilizados para trabalhar a cultura africana e Afro-brasileira nas escolas, $40 \%$ afirmaram trabalhar com livros, $25 \%$ vídeos, $10 \%$ músicas, 15\% danças, $5 \%$ jogos e $5 \%$ com outros materiais.

\section{CONSIDERAÇÕES FINAIS}

Diante da pesquisa realizada constatou-se que a lei 10.639/2003 vem sendo pouco trabalhada no cotidiano das escolas municipais contempladas. Os trabalhos realizados que abrangem a presente temática são abordados apenas na semana da consciência negra em valorização a cultura afro-brasileira e africana. Partindo do estudo realizado com professores da Escola municipal Dulcimar Brito, Maria Fernandes e Rui Barbosa, ambas no município de Tucuruí-Pa, chegaram-se as seguintes conclusões.

Os professores de educação física não trabalham a lei 10.639/2003 em suas práticas escolares por falta de conhecimento do tema, haja vista que quando questionados apenas $20 \%$ dos mesmos declararam conhecimento da temática, enquanto $80 \%$ pelo menos já ouviram falar a respeito. Esse indicativo aponta que a ausência desta discussão nas escolas se dá por falta de planejamento da instituição em trabalhar periodicamente a cultura étnico-racial, deixando de lado o que foi imposto pela lei há quatorze anos durante sua criação.

Os recursos didáticos que dão subsídio para os professores trabalharem os conteúdos atrelados à cultura afro-brasileira e africana mais utilizada nas escolas apontaram $80 \%$ os livros e os 
menos utilizados foram os jogos com apenas 5\%. Diante da constatação, seria interessante a parte didática voltar-se para a prática de movimento, dando ênfase a cultura corporal como as danças, lutas e os jogos que tanto valorizam a cultura africana e afro-brasileira.

A pesquisa aponta que são necessários mais estudos relacionados ao tema, que o poder público deveria gerar mais ações para capacitar os professores e profissionais de educação de modo que eles possam vivenciar de forma geral o exercício da lei 10.639/2003 eliminando o preconceito racial e respeitando as diferenças. Somando-se a isso, a escola tem como papel incluir frequentemente em seus conteúdos curriculares os valores e conhecimentos do diferentes discentes que frequentam esse âmbito escolar, de forma que possam desenvolver práticas pedagógicas que insira os variados públicos, sem distinção de raça, cor, sexualidade, gênero e religião.

\section{REFERÊNCIAS}

ABRAMOWICZ, Anete et al. Educação infantil, igualdade racial e diversidade: aspectos políticos, jurídicos, conceituais. Ministério da Educação, São Paulo, p.1- 220, 2012.

ALVES, Cynthia Cristina de Souza. O racismo na Escola e o Combate com Ações Pedagógicas. Universidade Estadual da Paraíba, Guarabira, p.1-20, 2012.

BORGES, Elisabeth Maria de Fátima. A Inclusão da História e da Cultura Afro- brasileira e Indígena nos Currículos da Educação Básica. 2010. 83 f. TCC (Graduação) - Curso de História, Universidade Estadual de Goiás (UEG), Goiás, 2010.

DUARTE, Angelina; SILVA, Ricardo Tadeu Caires. Análise dos projetos político-pedagógico das escolas do município de paranavaí-PR em relação ao cumprimento da lei n. ${ }^{\circ} 10.639 / 03$. Educere: XII congresso nacional de Educação, Paranavaí, p.1-14, 2015.

FERNANDES, José Ricardo Oriá. Ensino de história e diversidade cultural: desafios e possibilidades. Cad. Cedes, v.25, n.67, p378- 388, Campinas, 2005.

FERREIRA, Ricardo Frankllin; CAMARGO, Amilton Carlos. As Relações Cotidianas e a Construção da Identidade Negra. Psicologia: Ciência e Profissão, Maranhão, p.1-16, 2011.

FIGUEIREDO, Angela. Classe Média negra: Trajetórias e Perfis. Universidade Federal da Bahia, Salvador, p.1-2012, 2012.

GARCIA, Alessandra Agenor de Moura; SILVA, Marcio Pereira da; ALEXANDRE, Ivone Jesus. Desafios e perspectivas na formação de professores e a lei 10.639/03. Revista Eventos

Pedagógicos, Mato Grosso, p.1-9, 2012.

GIL, Antônio Carlos. Como Elaborar Projetos de Pesquisa. Atlas, São Paulo, p.1- 176, 2002.

GOMES, Nilma Lino. Educação, identidade negra e formação de professores/as: um olhar sobre o corpo negro e o cabelo crespo. Educação e pesquisa, n.1, p. 167- 182, 2003. 
GUEDES, Elocir; NUNES, Pâmela; ANDRADE, Tatiane de. O uso da lei 10.639/03 em sala de aula. Revista Latino-Americana de História. v.2, n.6, p. 422-430, 2013.

GUERRA, Elaine Linhares de Assis. Manual de Pesquisa Qualitativa. Grupo Ãnima Educação, Belo Horizonte, p.1-52, 2014.

LAKATOS, Eva Maria. MARCONI, Marina de Andrade. Fundamentos de metodologia científica. 5. ed. São Paulo: Atlas, 2003.

MARIOSA, Gilmara Santos; REIS, Maria da Glória dos. A influência da literatura infantil Afrobrasileira na construção das identidades das crianças. Estação Literária, Londrina, p.1-12, 2011.

Ministério da Educação. Diretrizes Curriculares Nacionais para a Educação das Relações ÉtnicoRaciais e para o Ensino de História e Cultura Afro-Brasileira e Africana. Brasília, 2004.

MOREIRA, Antonio Flávio; CANDAU, Vera Maria (org) 2008 Multiculturalismo. Diferenças culturais e práticas pedagógicas. Petrópolis: Vozes.

MOREIRA, Romilson do Carmo; VIANA, Cristina da Silva. Avanços e desafios na implementação da lei 10.639/2003: um estudo na rede municipal de ensino de Senhor do Bonfim/BA. Trilhas Pedagógicas, Salvador, p.1-18, 2015.

NEVES, Ana Maria Bergamin. Interações: raízes históricas brasileiras. São Paulo: Blucher, 2012.

SILVA, Francisco Thiago. Educação antirracista nos anos iniciais do ensino Fundamental no Distrito Federal: reflexões curriculares Dissertação (mestrado) - Universidade de Brasília, Faculdade de Educação / Programa de Pós-Graduação em Educação - PPGE, 2013.142 f

SILVA, Petronilha Beatriz Goncalves. Aprendizagem e Ensino das Africanidades Brasileiras. In: MUNANGA, Kabengele (org.). Superando o Racismo na escola. 2. ed. Brasília: Ministério da Educação, Secretaria de Educação Continuada, Alfabetização e Diversidade, 2005.

SILVA, Edna Lúcia da; MENEZES, Estera Muszkat. Metodologia da pesquisa e elaboração de dissertação, UFSC, 4. ed. Ver. Atual. Florianópolis 2005

SOUSA, Abraão Vitoriano de. Literatura infantil e questões étnico- raciais: por uma literatura afrobrasileira em sala de Aula. Revista de Pesquisa Interdisciplinar, Salvador, p.1-11, 2017.

SOUZA, Ana Lúcia Silva e CROSO, Camila (Coord.). Igualdade das relações étnico- raciais na escola: possibilidades e desafios para a implementação da Lei 10.639/2003. São Paulo: Petrópolis: Ação Educativa, CEAFRO e CERT, 2007. 93p.

SOUZA, Andréa C. Batista de. Educação e Diversidade Cultural: O impacto da cultura popular no espaço escolar. Extraprensa, São Paulo, p.1-21, 2009.

SOUZA, João Francisco. Prática Pedagógica e Formação de Professores. Eliete (Org.). Formação de Professores e Prática Pedagógica. Recife: Ed. Universitária da UFPE, 2009. 


\title{
NOTAS DE AUTOR
}

\section{AGRADECIMENTOS}

Não se aplica.

\section{CONTRIBUIÇÃO DE AUTORIA}

Não se aplica.

\section{FINANCIAMENTO}

Não se aplica.

\section{CONSENTIMENTO DE USO DE IMAGEM}

Não se aplica.

\author{
APROVAÇÃO DE COMITÊ DE ÉTICA EM PESQUISA \\ Não se aplica.
}

\section{CONFLITO DE INTERESSES}

Não se aplica.

\section{LICENÇA DE USO}

Os autores cedem à Motrivivência - ISSN 2175-8042 os direitos exclusivos de primeira publicação, com o trabalho simultaneamente licenciado sob a Licença Creative Commons Attribution Non-Comercial ShareAlike (CC BY-NC SA) 4.0 International. Esta licença permite que terceiros remixem, adaptem e criem a partir do trabalho publicado, desde que para fins não comerciais, atribuindo o devido crédito de autoria e publicação inicial neste periódico desde que adotem a mesma licença, compartilhar igual. Os autores têm autorização para assumir contratos adicionais separadamente, para distribuição não exclusiva da versão do trabalho publicada neste periódico (ex.: publicar em repositório institucional, em site pessoal, publicar uma tradução, ou como capítulo de livro), com reconhecimento de autoria e publicação inicial neste periódico, desde que para fins não comerciais e compartilhar com a mesma licença.

\section{PUBLISHER}

Universidade Federal de Santa Catarina. Programa de Pós-Graduação em Educação Física. LaboMídia - Laboratório e Observatório da Mídia Esportiva. Publicado no Portal de Periódicos UFSC. As ideias expressadas neste artigo são de responsabilidade de seus autores, não representando, necessariamente, a opinião dos editores ou da universidade.

\section{EDITORES}

Mauricio Roberto da Silva, Giovani De Lorenzi Pires, Rogério Santos Pereira

\section{HISTÓRICO}

Recebido em: 19 de junho 2019.

Aprovado em: 09 de março de 2020. 